\title{
DISSONÂNCIA MÉTRICA COMO ELEMENTO DE CONVERGÊNCIA ENTRE O ERUDITO E O POPULAR
}

\section{METRICAL DISSONANCE AS A CONVERGENCE ELEMENT BETUEEN THE CLASSICAL AND THE POPULAR}

\author{
Leandro Cumboski \\ Instituto Federal do Paraná - Campus Paranaguá \\ leandro.gumboski@ifpr.edu.br
}

\section{Resumo}

A música dos séculos XX e XXI apresenta um conjunto grande de especificidades, dentre as quais está a tensão entre os campos erudito e popular, conceitos que têm sido revisados no âmbito da emergência de uma indústria cultural, da reinvenção da orquestra clássica, do isolamento da chamada música "séria" contemporânea em centros universitários e do plano popular abrangendo um número cada vez maior de manifestações, muitas das quais díspares entre si, sob certos aspectos. A dissonância métrica é um elemento fortemente presente na sonoridade romântica da música de concerto do século XIX, sistematizada enquanto conceito a partir dos escritos de Hector Berlioz, com ampla contribuição da teoria musical recente. É, como tal, um dos tantos elementos que permanecem insistentemente nas mais diferentes manifestações musicais dos séculos XX e XXI. Este trabalho tem como objetivo indicar a existência de dissonâncias métricas em repertórios múltiplos, comumente identificados em contextos distintos a partir dos amplos e difusos campos do erudito e do popular. Revisase, inicialmente, definições e categorias de culturas, partindo-se para a identificação dos espaços fronteiriços entre cada categoria. Por fim, após se relacionar certo número de exemplos dos mais distintos contextos, conclui-se que a separação do erudito e do popular se torna inoperante, e que a dissonância métrica pode ser compreendida como um elemento de convergência entre ambos.

Palavras-chave: Dissonância métrica; Música Erudita; Música Popular; Séculos XX e XXI. 


\begin{abstract}
The music of the 20th and 21 st centuries presents a great set of specificities among which is the tension between the classical/art and popular fields. These two concepts that have been revised in the context of the emergence of a cultural industry, of the reinvention of the classical orchestra, of the called contemporary "serious" music being isolated in university, and of the popular field covering a growing number of manifestations, many of which are antagonistic in some respects. Metrical dissonance is an element strongly present in the romantic sonority of nineteenth-century concert music, and it was systematized as a concept from the writings of Hector Berlioz, with a broad contribution of recent music theory. It is one of the many elements that persistently remain in the most different musical manifestations of the 20th and 21 st centuries. This paper aims to indicate the existence of metrical dissonances in multiple repertories commonly identified in distinct contexts from the broad and diffuse fields of the classical/art and the popular. Definitions and categories of cultures are reviewed; frontier spaces between each category are identified. Finally, after relating several examples of the most distinct contexts, one concludes that the separation of the classical/art and the popular becomes inoperative, and that metrical dissonance can be understood as an element of convergence between the both.
\end{abstract}

Keywords: Metrical Dissonance; Classical Music; Popular Music; $20^{\text {th }}$ and $21^{\text {st }}$ Centuries.

\title{
Das categorias de cultura(s)
}

Cultura(s) - no plural -, nos diz Certeau (1998), é o trabalho resultante das formas de diferenciação que se articulam e cuja essência é mesmo maior que suas próprias representações ou suportes. Que se evite o princípio da autonomia à cultura, que estaria, para o filósofo francês, além dos sujeitos (MENESES, 1993), o que permanece é o reconhecimento da sua multiplicidade, sua própria pluralidade. Nosso pensamento cartesiano nos leva, desse modo, a propor - nominalmente categorias de culturas. Tais categorias surgem variavelmente e, por vezes, tangem objetos mais ou menos similares, convergindo na divergência dada por supostos limiares a priori que nos dariam respaldo para identificar aquilo que pertence a uma categoria e, por consequência, 
seus Outros. Não proponho nada diferente do habitual nesse sentido, embora eu me sirva, desta feita, dos conceitos erudito e popular na intenção final de turvar o limiar entre uma categoria e outra, apontando para a identificação de dissonâncias métricas em repertórios múltiplos. $\mathrm{Na}$ contramão de qualquer perspectiva universalista, portanto, acabo por salientar que, num contexto de cultura de massas, a distinção entre erudito e popular se torna inoperante (FRANCFORT, 2014).

Em que pese Alfredo Bosi ( 1992a; 1992b) voltar sua atenção para a realidade brasileira, seus apontamentos sobre cultura(s), do singular ao plural, são inequívocos: "Pode-se passar da raça para nação, e da nação para a classe social (cultura do rico, cultura do pobre, cultura burguesa, cultura operária), mas, de qualquer modo, o reconhecimento do plural é essencial" (BOSI, 1992b, p. 308). $\bigcirc$ autor, ademais, propõe uma análise de cultura(s) a partir de quatro campos, delimitados pelo erudito e pelo popular.

Se pelo termo cultura entendemos uma herança de valores e objetos compartilhada por um grupo humano relativamente coeso, poderíamos falar em uma cultura erudita brasileira, centralizada no sistema educacional (e principalmente nas universidades), e uma cultura popular, basicamente iletrada, que corresponde aos mores materiais e simbólicos do homem rústico, sertanejo ou interiorano, e do homem pobre suburbano ainda não de todo assimilado pelas estruturas simbólicas da cidade moderna (BOSI, 1992b, p. 308).

Os quatro campos propostos, a partir daquela definição, seriam: cultura universitária, cultura criadora extra-universitaria, indústria cultural e cultura popular (BOSI, op. cit.). Quatro eixos, ainda que distintos, também são propostos por Rössel e Otte (2010): alta cultura, cultura popular, cultura folclórica e cultura jovem. A terminologia que nos chama a atenção pela insistência na utilização de adjetivos sintomáticos de uma perspectiva hegemônica - "alta" cultura, pois que está acima simbolicamente das demais -, demonstra, a partir dos eixos restantes, uma fragmentação tripartite de todo o espectro que Bosi (1992b) anteriormente identificava em dois campos, o popular e o da indústria cultural. $\bigcirc$ folclórico, aqui (RÖSSEL; OTTE, 2010), é toda manifestação de caráter popular, porque espontâneo, que não se utiliza de amplos 
meios de gravação e reprodução, configurando aquilo que por vezes nos referimos como "regional" e que, em geral, é objeto direto da atenção de organizações cuja função é a de estabelecer e salvaguardar patrimônios culturais. A "cultura jovem", por sua vez, compreende um espaço específico dentro do genérico campo do popular, consistindo em paradigma por vezes estereotipado da indústria cultural; seus exemplares seriam demasiadamente efêmeros, em conteúdo e recepção. Tal efemeridade, ainda, parece reprimir qualquer sentido de tradição, favorecendo a falta de pertencimento por aquilo que está, afinal, de passagem; é o próprio não-lugar (Cf. AUCÉ, 2013) cultural. Na anedota composta por Sérgio Britto e Branco Mello para Os Titãs na faixa título do álbum, é "a melhor banda de todos os tempos da última semana"1. Nos escritos de Adorno (Cf. CARONE, 2003), são os "Babbitts"2 musicais.

Há ainda quem vislumbre funcionalidades epistemológicas num modelo tripartite, afeiçoado pelos planos popular, erudito e da indústria cultural ou cultura de massa (SOUZA, 2010), ao passo que outros optam por um paradigma tripartite alicerçado pelos campos erudito, folclórico e popular (BÉHACUE, 2006). Voltamo-nos, enfim, ao modelo bipartite erudito e popular, que parece ser mais recorrente na bibliografia disponível (COMES, 1992; ZUMTHOR, 1997; WISNIK, 2007, 2017; ROSA; BERG, 2018). Um modelo conceitual em dois planos permite-nos maiores generalizações que ora ou outra são relativizadas conforme o propósito de quem fala e é compreendido, espera-se, por seu interlocutor. Digna de nota é a proposta de Lahire, citado por Francfort (20|4), ao apresentar os conceitos de cultura "fria" e "quente"; a primeira associada à contemplação passiva; a segunda ao consumo ativo, agitado e, por vezes, dançável. Logo, uma suíte em seu contexto original configuraria exemplo de cultura quente, manifestada aos passos de danças sob festas aristocráticas com consumo de comida e bebida, enquanto uma apresentação de João Gilberto no Theatro Municipal do Rio de Janeiro concebe um exemplo de cultura fria. Nem sempre o erudito é "frio" e nem sempre o popular é "quente".

I $\bigcirc$ exemplo é propositado uma vez que a própria banda, no entendimento geral do academicismo musicológico, figura como um dos tantos exemplos do que identifiquei, agora, como "cultura jovem". A metacrítica não proposital, portanto, ainda traz versos sarcásticos como "quinze minutos de fama / depois descanse em paz", como se o nível e o tempo de fama de uma dada peça ou compositor/grupo musical devesse configurar critério de juízo de valor.

2 "Referência ao personagem George Babbitt, de Sinclair Lewis, que simboliza a mediocridade cultural do homem norte-americano" (CARONE, 2003, p. 491). 
Desse modo, essa breve exposição inicial nos serviu para demonstrar a existência do plural - insisto - e nos lembrar de práticas que não raramente são imediatamente esquecidas quando iniciamos a escrita ou leitura de um texto musicológico que se propõe analítico, como no presente caso. Antes de partir para tais exemplos analíticos, chamo a atenção para os espaços fronteiriços, que surgem do diálogo entre campos aparentemente distintos.

Na verdade, o que a palavra erudito designa é uma tendência, no seio de uma cultura comum, à satisfação de necessidades isoladas da globalidade vivida, à instauração de condutas autônomas, exprimíveis numa linguagem consciente de seus fins e móvel em relação a elas. Popular, tendência a alto grau de funcionalidade das formas, no interior dos costumes ancorados na experiência cotidiana, com desígnios coletivos e em linguagem relativamente cristalizada (ZUMTHOR, 1993, p. 119).

\section{Das mediações entre as categorias de cultura(s)}

A tarefa de pensar conceitualmente categorias de culturas a partir de espaços delimitados não é, como vimos, tarefa fácil. Em geral, no esforço de ponderar as mais distintas manifestações culturais a partir de aspectos gerais que ora se repetem em outras, ora singularizam a própria manifestação, acabamos por identificar certo número de práticas que transitam entre categorias distintas aparentemente bem delineadas. Os caminhos aqui são muitos, de mão simples e dupla. Esbarraríamos, igualmente, numa leitura mais aprofundada da situação, em conceitos centrais, tais como enculturação, inculturação, aculturação, transculturação, que não tratarei aqui.

Os séculos XX e XXI, conquanto não exclusivamente, compreendem um período particularmente rico no que tange às mediações entre categorias culturais distintas, visto que "há um vazamento daqueles bolsões que separavam tradicionalmente o erudito e o popular" (UISNIK, 2017, p. 13). Francfort (20|4), ao reconhecer pela insignia de transferência o processo de apropriação de valores do contexto popular pelas práticas eruditas, propõe o conceito de contratransferência para identificar o movimento contrário: o erudito no popular. Nesse sentido, Bessa (2010) aponta para um processo de "contaminação da música

\section{4}

REV. TULHA, RIBEIRÃO PRETO, v. 5, n. 1, pp. 60-86, jan.-jun. 2019 
popular por um tipo de escuta e de valoração estética oriundos da chamada "música culta"' (BESSA, 2010, p. 57). Esta última "se caracterizaria pela busca da abstração, pelo cultivo da música pura, desvinculada tanto da palavra (texto poético), como do corpo (dança/ritual)" (Ibid., p. 57). Tal definição, contudo, é tanto mais coerente ao grupo de compositores independentes, não mais músicos-artesões, "de Beethoven a Stravinsky, grosso modo" (CASTRO, 20 10). Prática musical que se torna, enfim, fria (LAHIRE apud FRANCFORT, 2014). A esta música popular muito particular, que se apropria de valores tipicamente associados ao erudito e, mais propriamente, àquele do século XIX, Fischerman (2004) dá a alcunha de "música artística de tradição popular" - "um grupo de músicas que, muito além de suas funcionalidades sociais, são escutadas como música" (FISCHERMAN, 2004, p. 19, tradução minha).

Todos esses espaços de transição, de mediação, de privação de certos purismos estéticos, configuram aquilo que Canclini (1995) chama de "fronteiriço". Além deste último, Bosi (1992a), Rosa e Berg (2018), Martín-Barbero (2001) e Zumthor (1997) também destacam relações de transculturação em situações de encontro do erudito com o popular, ou do erudito no popular, ou do popular no erudito. Esses espaços fronteiriços são particularmente relevantes quando analisamos casos e casos de dissonância métrica na música dos séculos XX e XXI. A dissonância métrica, portanto, não aparece apenas na convergência do erudito com o popular, mas nos espaços fronteiriços, em repertórios que transitam entre um contexto e outro. Aparece, afinal, na própria inoperância da distinção entre o erudito e o popular.

\section{Da dissonância métrica}

Há dissonâncias rítmicas, há consonâncias rítmicas e há modulações rítmicas; nada mais óbvio. $\bigcirc$ emprego engenhoso de um e outro é muito difícil, é verdade, especialmente porque acreditamos que não se pode ensinar mais do que a arte de inventar belas melodias; mas querer reduzir o ritmo ao papel mesquinho que the tem sido dado por tanto tempo é tão inútil e insano quanto era, à época de Monteverdi, tentar impedir a invasão da dissonância na harmonia (BERLIOZ, 2015 [ 1837], tradução minha). 
A citação de Hector Berlioz (1803-1869), extraída de um artigo crítico de jornal publicado a 10 de novembro de 1837 (BERLIOZ, 2015), traduz um sentimento de época. Se se propõe tal metáfora a partir da identificação da tensão resultante - tensão a ser resolvida, até então -, é verdade que a correspondência cronológica entre ambos os fenômenos - dissonância harmônica e dissonância métrica - é deveras defasada. A primeira teria sido introduzida no ocidente, para Berlioz, à época de Claudio Monteverdi (1567-1643), enquanto a segunda, somente em sua própria época. É verdade também que há célebres casos anteriores de dissonâncias métricas no repertório de concerto, mas eles parecem configurar situações isoladas sem cumprimento de qualquer tipo de função formal padronizada, como já nos fala Berlioz. Em Mozart encontramos alguns exemplos mais evidentes de casos assim; vide, e.g., o Minuetto da sua Sinfonia em Sol menor, K. 550 (COHN, 1992), ou, igualmente, o Minuetto ao final da ópera Don Giovanni, K. 527, em que presenciamos a sobreposição de três danças - de origens sociais distintas - que, juntas, configuram uma categoria específica de dissonância métrica. Que se observe que, especialmente neste último caso, a dissonância métrica não tange qualquer tipo de função formal de transgressão, de tensão a ser preparada e resolvida, mas sim de função dramática em virtude do quadro da ópera. Situação tão original que não fora mais repetida em outras composições.

Mas o que é, afinal, dissonância métrica? O conceito, como vimos, surge em meio aos escritos teórico-analíticos do século XIX, mas não aparenta ser, ao menos na perspectiva atual, tão óbvio quanto anuncia Berlioz. Há certo número de teóricos mais recentes que procuraram contribuir com o assunto, dos quais poderíamos citar Yeston (1976), que ainda se utiliza do termo "dissonância rítmica", tal qual Berlioz, e Berry (1987), que lança mão da expressão "dissonância métrica" para se referir a situações de não congruidade vertical, compreendendo um tipo de polimetria em que "a barra de compasso real é disjunta, não 'perpendicular' à 'linha' da sucessão temporal" (BERRY, 1987, p. 365, tradução minha). O conceito, enfim, ganha novos rumos com o trabalho de Krebs (1999), a primeira e uma das poucas publicações extensas integralmente dedicada ao assunto. Produções recentes afins, como, por exemplo, a de Wilson (20 16), no geral têm Krebs ( 1999) como o principal alicerce referencial. É, portanto, a partir de Krebs (1999) que conceituo metro e dissonância métrica e apresento excertos analíticos ao longo deste artigo. 
Para Krebs (1999), metro é, essencialmente, uma estrutura multinevelada resultante da união dos distintos estratos que compõem um dado trecho musical. Note-se que metro não é entendido aqui como uma estrutura a priori, necessariamente regular, previsivel e redutível às fórmulas de compasso (Cf. CUMBOSKI; MOREIRA, 2018). Aqui, metro está associado, portanto, às diferentes camadas texturais que compõem certo segmento musical e está sujeito às nuances existentes no próprio fluxo musical. $\bigcirc$ alinhamento entre dois estratos distintos forma uma consonância primária (KREBS, 1999). Destarte, uma estrutura métrica, seja ela consonante ou dissonante, apresenta regularmente três setores de estratos métricos: o estrato de pulso, os niveis interpretativos e o nível de micropulsos (KREBS, Op. cit.). Uma dissonância métrica, para Krebs (1999), é caracterizada por algum grau de desalinhamento entre os tempos/beats/pulsos (doravante, tempos) que compõem estratos métricos distintos, estratos estes em niveis interpretativos (acima do estrato de pulso). $\bigcirc$ estrato de pulso é, normalmente, um estrato em comum - alinhado - a todos os demais que estão acima dele próprio, inclusive os estratos em desalinhamento métrico. Os níveis de micropulsos, portanto, compreendem os níveis mais rápidos, acelerados, de qualquer estrutura métrica, englobando, por vezes, a movimentação - kinesis dada por ornamentos.

Dentre outros meandros da teoria de Krebs (1999), para os quais recomenda-se enfaticamente consultar a obra original ${ }^{3}$, destaco os elementos principais de sua taxonomia. Inicialmente, distinguem-se as dissonâncias por agrupamento das dissonâncias por deslocamento: as primeiras caracterizadas por estratos métricos representados por números não múltiplos; as segundas, por estratos com estruturações internas de tempos equivalentes, mas deslocados temporalmente um em relação ao(s) outro(s). Partindo dessas categorias como nosso aforismo, pretendo evitar, nesse momento, qualquer tipo de proselitismo teórico na intenção de introduzir possíveis novos elementos desta teoria ao longo das análises que se seguem, na crença, também, de que os aspectos principais da teoria fiquem mais claros com as exemplificações que trago à luz. Não percamos de vista o objetivo que expus ao início, em pensar a dissonância métrica como elemento em comum a repertórios múltiplos, associados a distintos contextos de produção e recepção.

3 Para uma lacônica revisão dos principais aspectos dessa teoria, posso recomendar a leitura de Gumboski (2018). 
Os excertos analíticos a seguir seguem, desse modo, os grafismos da própria teoria de Krebs (1999)4.

\section{Dissonância métrica em exemplos de repertórios eruditos e/ou populares}

A teoria da dissonância métrica nasce no âmago do repertório de concerto do século XIX. Observemos, a título de exemplo, os trabalhos de Krebs (1999) e Benjamin (2011) sobre Schumann; de Smith (2001) e Bosworth (2012) sobre Brahms; de Dodson (2009) sobre Chopin; de Krebs (2014) sobre Schubert; e de Malin (2010) sobre o lied germânico. Todavia, mais recentemente certo grupo de pesquisadores tem se dedicado a analisar a existência de dissonâncias métricas, nos termos de Krebs (1999), em repertórios do século XX, notadamente identificados como manifestações de caráter popular. Novamente, a título de exemplo, notemos os trabalhos de Waters (1996) e Love (2013) sobre o jazz; de Pieslak (2007), McCandles (2010) e Biamonte (20|4) sobre o rock; e o de Butler (2006) sobre a dance music eletrônica.

Doravante, procuro não mais frisar a partir de critérios particulares se considero que um exemplo tende mais ao popular ou ao erudito. Deixo essa definição a critério do leitor, mas ela, em si, não é mais relevante, dado que meu objetivo é justamente o de salientar a inoperância desta distinção (FRANCFORT, 2014) a partir da identificação de um elemento - a dissonância métrica - estruturalmente em comum. Desse modo, os excertos analíticos a seguir estão organizados basicamente por razões cronológicas, de modo que o contexto de produção e recepção de cada um varia sensivelmente. Ao leitor, pode parecer que recorro ao método indutivo, apoiando-me em casos isolados e peculiares que

\footnotetext{
4 Neste modelo analítico, os números representam as distâncias temporais entre um instante e outro, instantes alinhados com eventos considerados importantes metricamente em seus próprios contextos - importância que, por sua vez, é atribuída tendo-se como critério tendências da percepção auditiva descritas em trabalhos como o de Lerdahl e Jackendoff (1983) e London (2012). Uma vez que se trata de uma distância temporal, as pausas precisam ser consideradas. Ainda, números entre parêntesis indicam certa diminuição na rigidez da sensação métrica e costumam aparecer visualmente nos exemplos analíticos em situações de dissonância por deslocamento menos acirrada (o evento que gera o deslocamento é efêmero e deturpa ligeiramente a regularidade métrica previsivel pela lei da boa continuidade) ou de dissonâncias indiretas (em que a indicação numeral entre parêntesis normalmente está alinhada com o estrato métrico mantido mentalmente pela lei da boa continuidade, em conflito, neste caso, com o estrato métrico que passou a acontecer na superfície melódica).
} 
pouco representariam um quadro geral de repertórios entre os séculos XIX e XXI, nos quais, posso afirmar, as dissonâncias métricas são uma constante. Os exemplos que trago à tona, entretanto, são meramente exemplificativos; um número muito maior de casos pode ser verificado nos trabalhos analíticos que referencio ao longo deste artigo. Há, também, muitos casos de repertórios dos quais não encontramos análises que expõe a existência de dissonâncias métricas, ainda que elas estejam lá. repertório não depende da análise para existir, afinal.

Inicialmente, sinto-me na obrigação de apresentar ao menos um excerto analítico de uma composição de Berlioz. Uma análise aprofundada nos revelaria um caráter quase didático da sua Sinfonia Fantástica (BERLIOZ, 1900 [ 1830$]$ ) no que diz respeito à sistematização de dissonâncias métricas. A Fig. I ilustra uma das muitas situações de dissonância por agrupamento no segundo movimento da composição. Repare que o desalinhamento identificado pelos agrupamentos em "8" e " 6 " (tendo como unidade do estrato de pulso a figura de semicolcheia) associados às partes do violoncelo e primeiros violinos (em " 8 ") e violas e segundos violinos (em " 6 ") coincide com um momento de suspensão harmônica, cuja resolução acontece nos compassos imediatamente posteriores à resolução da dissonância métrica ao final deste excerto. Os sopros presentes neste trecho estão alinhados com o estrato já identificado nas partes da viola e segundos violinos.

Mais conhecido por sua fantasia sobre temas brasileiros intitulada A Sertaneja, Brasílio Itiberê da Cunha compôs, por volta de 1882, sua $6^{\text {a }}$ Mazurka (ITIBERÊ, ca. 1882). A seção de abertura da peça ilustra uma situação de dissonância subliminar (ver Fig. 2) - quando o metro que soa não corresponde ao metro notado, de modo que o conflito métrico em si pode ser mais ou menos explicitado pelo intérprete; daí o caráter subliminar da dissonância. Tal desalinhamento, no caso desta peça, ocorre ainda com um processo métrico (KREBS, 1999) em que identificamos a alteração de uma dissonância subliminar por agrupamento para uma dissonância subliminar por deslocamento até, enfim, ser resolvida em consonância (suprimida na ilustração abaixo). Na Fig. 2, com vistas à praticidade da notação analítica, toma-se a colcheia como figura de referência - estrato de pulso; já o estrato subliminar, associado à própria notação de compassos e ao "anúncio" de que se trata de uma Mazurka, logo em metro ternário, está identificado entre colchetes (agrupamentos em " 6 "). 

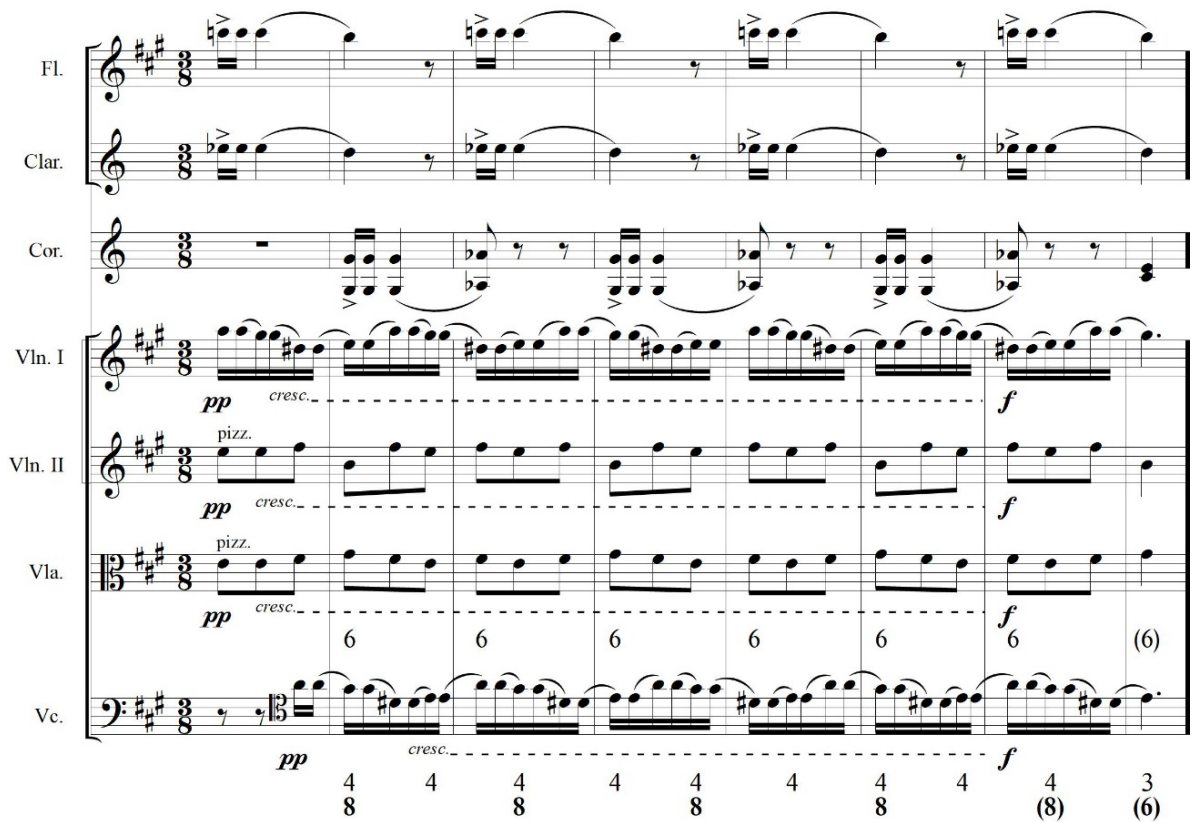

Figura 1: Dissonância por agrupamento no segundo movimento da Sinfonia Fantástica de Berlioz (1900 [1830])
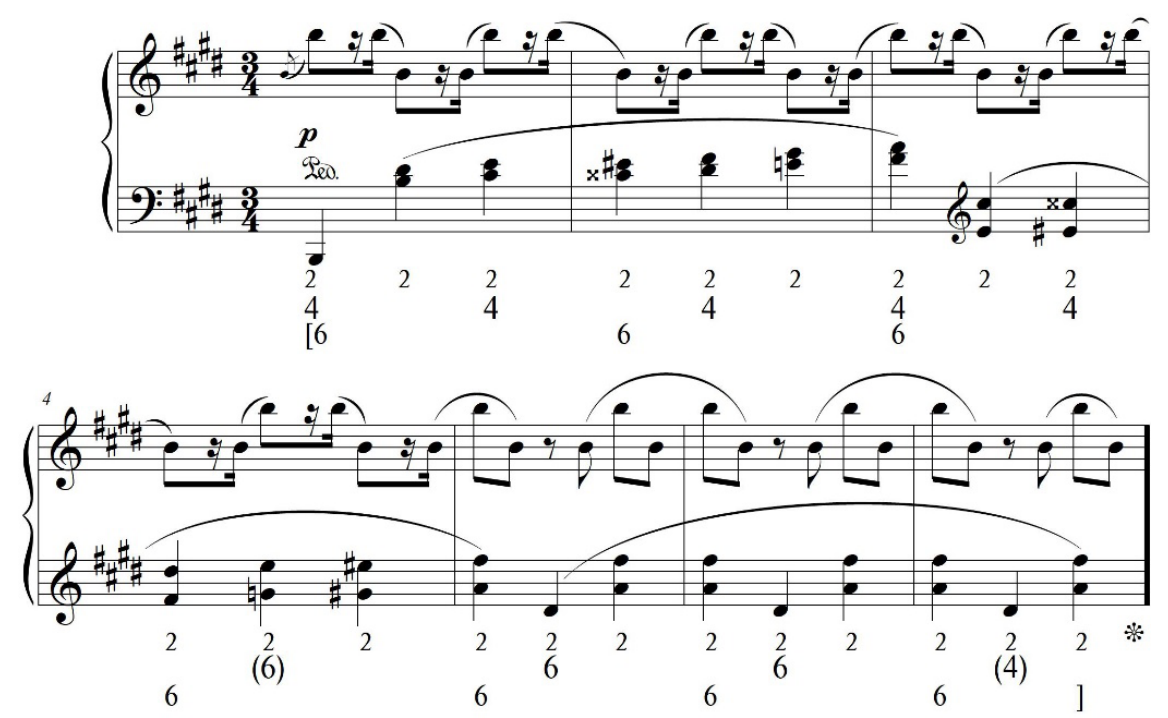

Figura 2: Dissonâncias subliminares por agrupamento (compassos 1-3) e por deslocamento (compassos 4-7) na $6^{\circ}$ Mazurka de Itiberê (ca. 1882) 
Já no início do século XX encontramos outro caso de dissonância métrica na música brasileira para piano. Composta em 1910, Odeon é uma das peças mais conhecidas de Ernesto Nazareth. Identificada em partitura (NAZARETH, 1968 [1910]) como um "tango brasileiro", a peça apresenta no fechamento (Fig. 3) de seu tema principal uma figura rítmica na iminência de uma dissonância por deslocamento; figura rítmica que, ademais, é facilmente encontrada em muitos exemplares de choro.

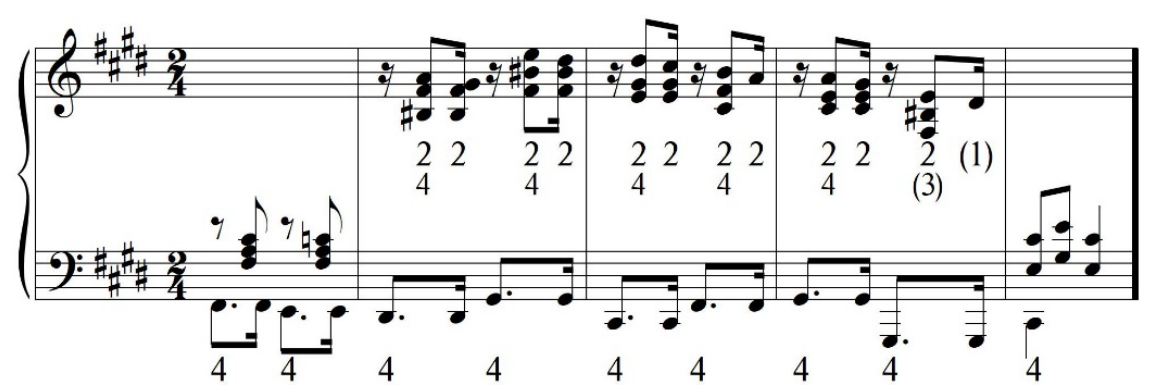

Figura 3: Dissonância por deslocamento em Odeon de Nazareth (1968 [1910])

Entre 1914 e 1916 Gustav Holst desenvolveu sua composição mais conhecida: The Planets, uma suite em sete movimentos. Em "Saturno", o quinto movimento da obra, encontramos um bom exemplo de dissonância por deslocamento. Escolhi este excerto propositalmente para ilustrar, também, uma situação de externalização [surfacing] (KREBS, 1999), em que uma dissonância subliminar se torna externa [surface]. A Fig. 4 traz os primeiros compassos do movimento supracitado a partir do arranjo para dois pianos feito pelo próprio compositor (HOLST, 1979). 


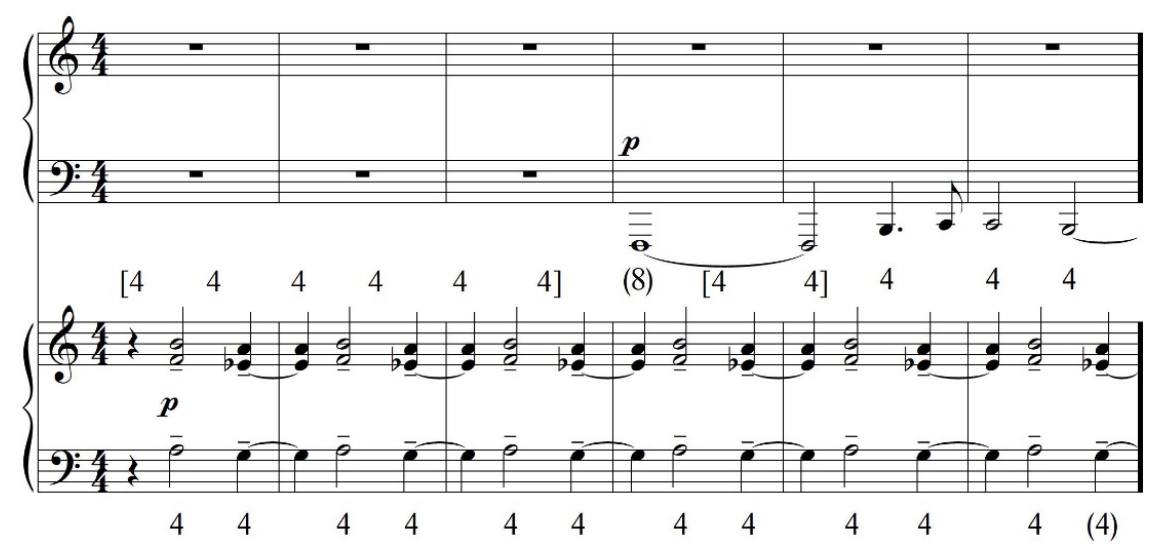

Figura 4: Processo de externalização no início do quinto movimento ("Saturno") da obra The Planets, Op. 32, de Gustav Holst (1979), em que a dissonância subliminar (compassos 1-3) passa à dissonância externa (compassos 4-6).

Recentemente demonstrei a existência de múltiplas categorias de dissonâncias métricas em L'Histoire du Soldat, de Stravinsky (CUMBOSKI, 2017), obra composta em 1918, que se utiliza de um instrumental consideravelmente reduzido, se comparado aos dos ballets anteriores, bem como de materiais como ragtime. Um ano depois Pixinguinha finalizava Um a Zero, composição que ficou conhecida a partir das gravações feitas entre 1946 e 1950 em contraponto com Benedito Lacerda (CALDI, 1999). $\bigcirc$ tema da composição, que parece ter sido inspirado na transmissão radiofônica da partida entre Brasil e Uruguai pela final do Campeonato Sul-Americano de 1919, cujo placar final é o título da peça, apresenta uma dissonância por agrupamento de estruturação tal que se repete em muitos outros trechos da composição, com algumas variações melódicas. $\bigcirc$ excerto da Fig. 5 se utiliza do conteúdo da transcrição feita por Sève e Gang (2010-2011). 


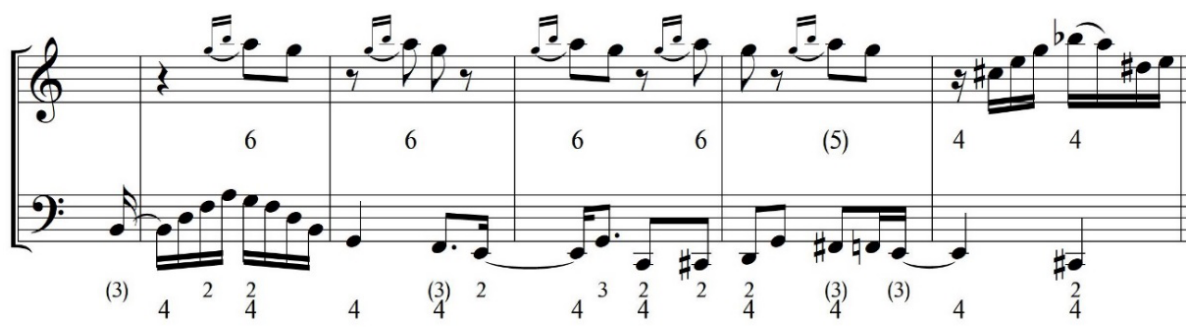

Figura 5: Dissonância por agrupamento na seção A de Um a Zero, de Pixinguinha [1919] (SËVE; GANG, 2010-2011).

Ainda no âmbito da música brasileira, não há como deixar VillaLobos de fora desse lacônico levantamento de exemplos que ora faço. A título de ilustração, relembro a peça Choros ( $N^{\circ}$. 1) para violão, datada de 1920 (VILLA-LOBOS, 1960), cuja dedicatória a Nazareth aparece não apenas em subtítulo ao início da partitura, mas estruturalmente, entre outros aspectos, em sua cadência final (Fig. 6), com situação de dissonância métrica por agrupamento similar à da Fig. 3. Já na peça Choros (N. 2) (VILLA-LOBOS, 1927 [1924]), com dedicatória à Mário de Andrade e com influência mais visível de Stravinsky ${ }^{5}$, observamos uma quantidade muito mais expressiva de trechos em dissonância métrica entre as partes de flauta e clarinete; a peça como um todo é um continuum de processos em dissonância métrica. A Fig. 7 exemplifica uma situação encontrada no trecho referente ao número de ensaio " 7 ".

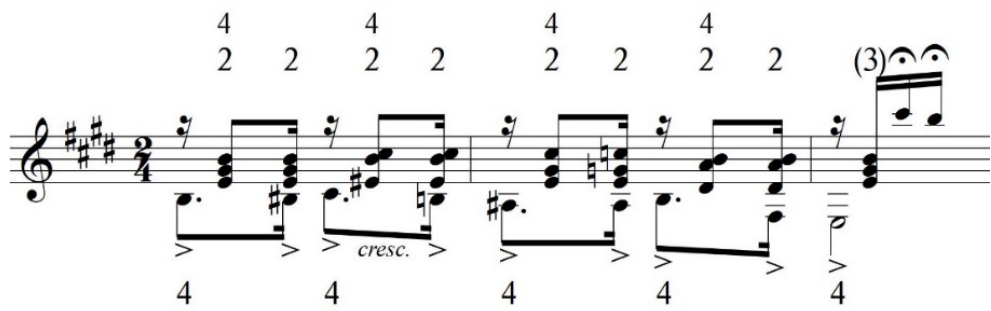

Figura 6: Dissonância por deslocamento em Choros (№. 1), de Villa-Lobos (1960 [1920]).

5 Van Den Toorn (2012) demonstra a existência de dissonâncias métricas em obras do "período russo" de Stravinsky, conquanto não se apoie diretamente no termo e na teoria de Krebs (1999). 

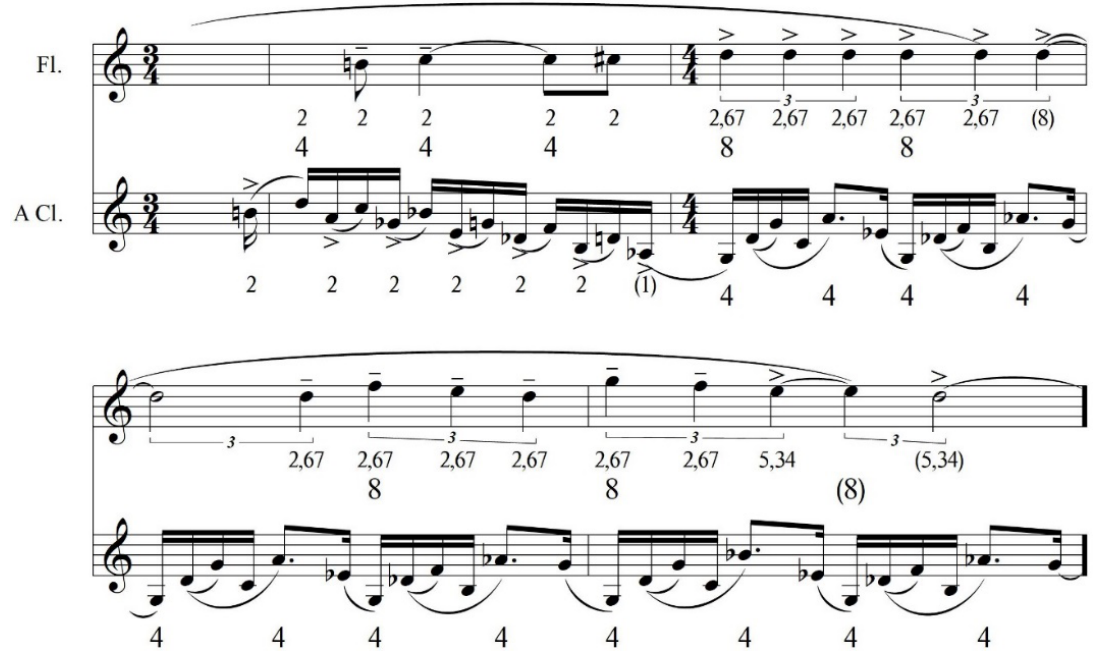

Figura 7: Dissonância por deslocamento seguida de dissonância por agrupamento em Choros (№. 2), de Villa-Lobos (1927 [1924]).

Contemporâneo de Villa-Lobos, Béla Bartók compôs um bom número de peças com estruturas metricamente dissonantes. Um exemplo que trago à tona ilustra uma situação de dissonância composta, quando há mais de dois estratos métricos em conflito. No segundo movimento da Música para cordas, percussões e celesta (BARTÓK, 1939 [1936]) observamos um processo métrico que transfigura uma dissonância simples (dois estratos em conflito) em uma dissonância com três estratos desalinhados (Fig. 8). 

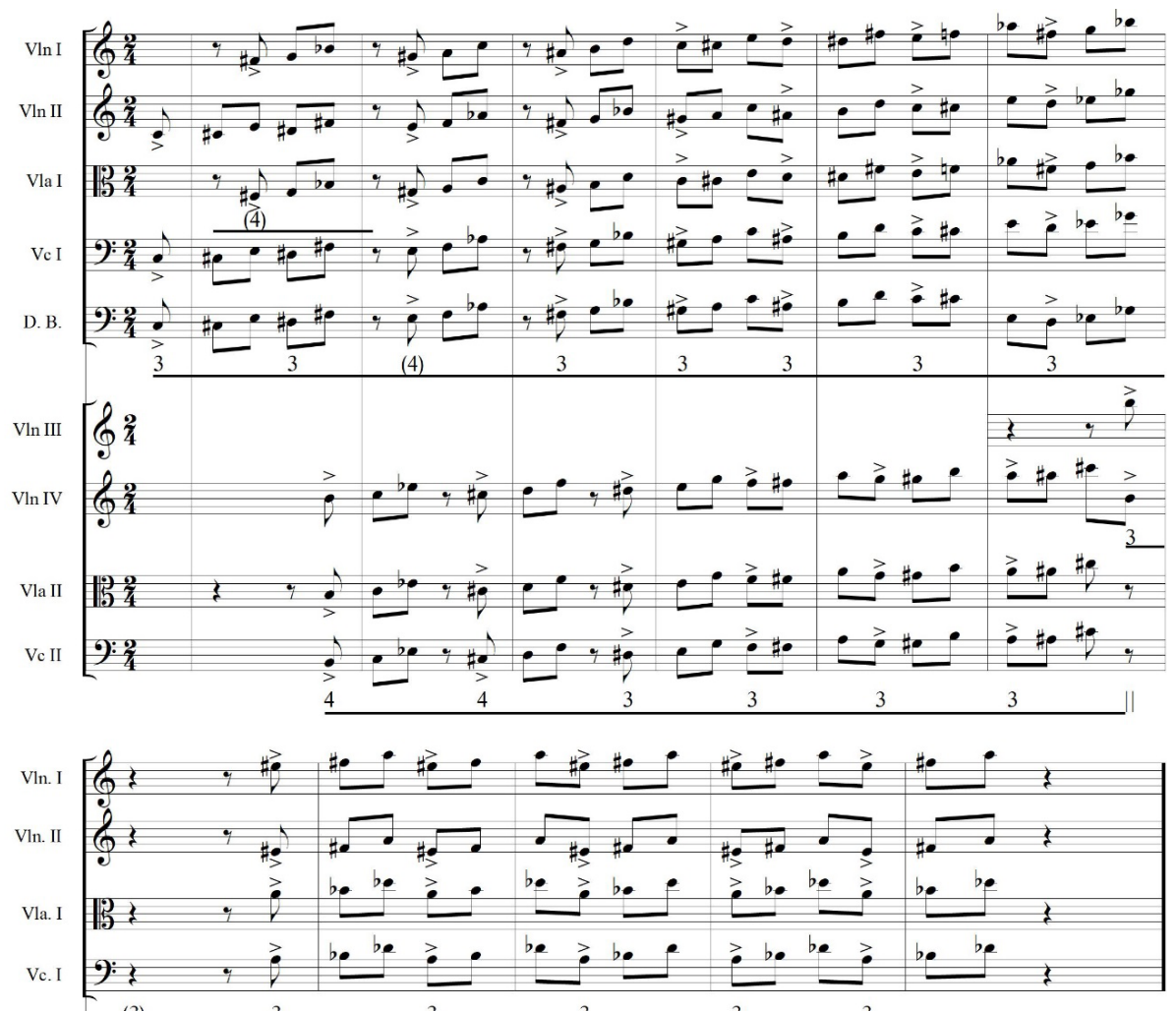

(3)

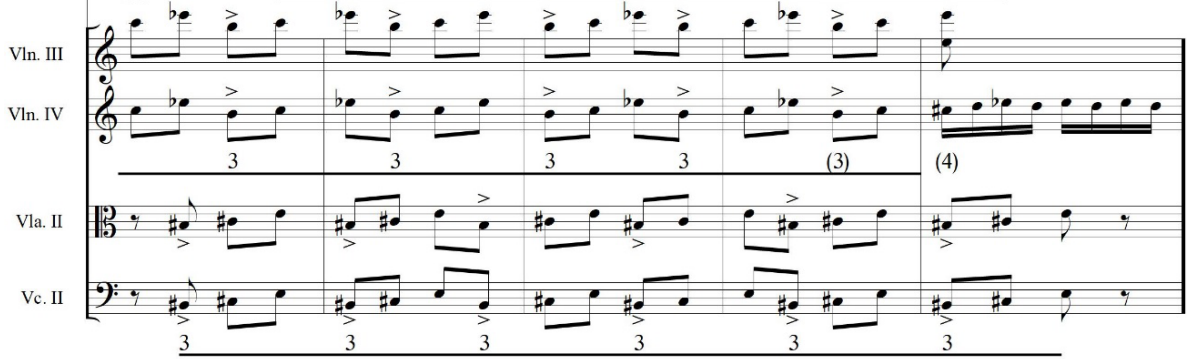

Figura 8: Dissonância por deslocamento no segundo movimento da Música para cordas, percussão e celesta de Bartók (1939 [1936]).

A década de 1960 produziu grande quantidade de práticas metricamente dissonantes. O Poème Symphonique (1962) de György Ligeti é emblemático, dado que o símbolo máximo da metrificação 
musical - o metrônomo - é utilizado para gerar uma sonoridade amétrica, essencialmente textural. A relação entre as estruturas métricas exercidas por cada um dos cem metrônomos, todavia, é deveras dissonante. Só percebemos esta relação ao final da performance, quando resta ao ouvinte a energia de alguns poucos metrônomos sobrepostos. Tal dissonância métrica, que chamo aqui de latente, dada sua inaudibilidade, é marcadamente composta. Surgido na mesma década, o movimento minimalista desenvolveu incontáveis situações de dissonâncias métricas, muitas das quais resguardando latência similar à da peça de Ligeti. Este é o caso, por exemplo, de In C, de Terry Riley (1989 [1964]), em que são sobrepostos até cinquenta e três motivos melódico-rítmicos com periodicidades desiguais, gerando uma dissonância por agrupamento consideravelmente densa. Já em Piano Phase, Steve Reich ( 1980 [1967]) explora complexas relações de dissonâncias por deslocamento, num processo conhecido como phase shifting. Também dos anos de 1960 podemos ouvir incontáveis situações de dissonância métrica na música para big bands de compositores como Don Ellis e Stan Kenton.

De considerável relevância para o desenvolvimento de dissonâncias métricas ao longo da histórica musical ocidental são o rock n' roll e o rock progressivo. Prezando pela objetividade, cito o caso relativamente mais simples de Kashmir, composta e gravada pela banda Led Zeppelin em 1975. Na Fig. 9 apresento uma transcrição simples da relação metricamente dissonante estabelecida entre a parte da bateria de John Bonham e uma redução das partes das cordas que recortam certas seções da peça, como a introdução.

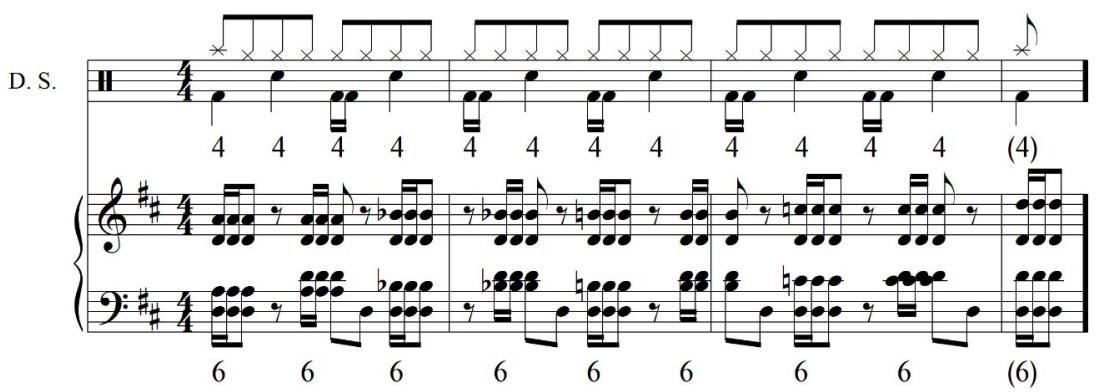

Figura 9: Dissonância por agrupamento em Kashmir de Led Zeppelin [1975]. 
Em Short Ride in A Fast Machine, John Adams (1986) se utiliza, tal qual certos compositores do supracitado movimento minimalista, da sobreposição de agrupamentos melódico-rítmicos com durações distintas, gerando desalinhamentos métricos que tendem a passar despercebidos pelo ouvinte cujo foco se dirige à sonoridade geral da composição. Também da década de 1980 são os primeiros bailes de dance music eletrônica marcados pela execução de house e techno, práticas que têm como um de seus aspectos estruturais fundamentais - uso de dissonâncias métricas (BUTLER, 2006). Convido o leitor a escutar um exemplo pouco mais recente, de 1997, do grupo de música eletrônica The Chemical Brothers: a peça Piku, que compõe o disco Dig Your Oun Hole (1997), inicia com uma interessante dissonância por deslocamento, um daqueles tantos casos em que a parte com estrato deslocado aparece antes ao ouvinte do que a(s) parte(s) que se torna(m) referência(s) de percepção do chamado nivel primário (KREBS, 1999), i.e., aquele nível métrico associado ao próprio tactus, na definição de Lerdahl e Jackendoff (1983). Para dar exemplos mais recentes de casos similares, o leitor pode buscar pelas peças 3 Words, de Cheryl Cole (ft. will.i.am), de 2009, e Sex On Fire, gravada em 2008 por Kings of Leon ${ }^{6}$. Para este último, a título de ilustração, transcrevo uma versão simplificada analiticamente na Fig. 10.

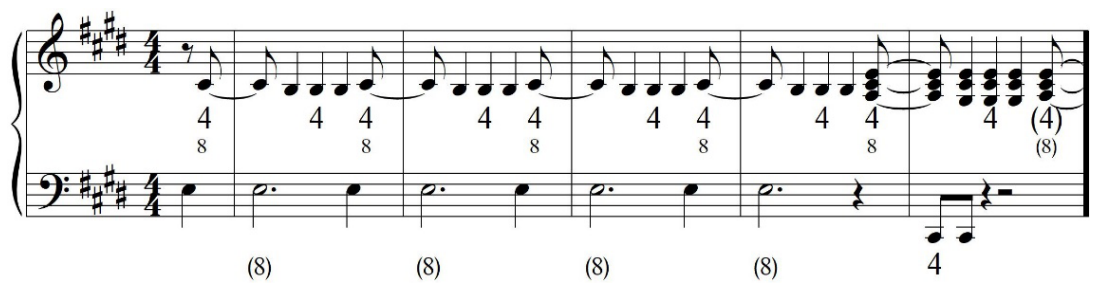

Figura 10: Dissonância por deslocamento no início de Sex On Fire, de Kings of Lion [2008].

6 Desta peça, especificamente, já presenciei a tentativa frustrada de execução de algumas bandas, em geral de caráter amador, por conta desta dissonância por deslocamento. 
Por fim, voltando nossa atenção ao interiorano e ao suburbano, descritos por Bosi ( $1992 \mathrm{~b}$ ), que evito associar ao popular neste momento, encontraremos exemplos de hemiolas que, se entendidas enquanto conflitos entre agrupamentos não múltiplos, como $2 \times 3$ ou $4 \times 6$, são, em suma, estruturas metricamente dissonantes. As diferentes bases ritmicas que ouvimos em manifestações do Funk Carioca (Volt Mix, Tamborzão, Beatbox, Pancadão, etc.), são, em geral, com estruturas de relações binárias entre os níveis métricos (Cf. as transcrições de CACERES; FERRARI; PALOMBINI, 2O 14). Entretanto, não é difícil encontrar estas mesmas bases em conflito com estratos de agrupamentos ternários, exercendo algum tipo de hemiola. Em alguns casos, como Hoje eu não vou dar - Eu vou distribuir (2013), de Valesca Popozuda, o estrato ternário até mesmo predomina sobre o binário. Um exemplo muito menos suburbano, já bem internacionalizado, é o de Bola Rebola, lançado por Tropkillaz, J Balvin, Anitta e Mc Zaac em 2019, em que a base rítmica é predominantemente binária, mas partes dos trechos cantados por J Balvin (e.g., entre 1'57" e 2'।3") criam situações de dissonâncias métricas por agrupamento a partir de hemiolas, sejam diretas (sobrepostas à própria base), sejam indiretas (sobrepostas à sensação binária já interiorizada pelo ouvinte a partir de inúmeras outras frases cantadas ao longo da música). A Fig. 11 procura ilustrar analiticamente este tipo de desalinhamento métrico. mesmo tipo de dissonância métrica pode ser encontrado em práticas brasileiras mais interioranas, como, por exemplo, em manifestações de Maculelê nos estados das regiões nordeste e sudeste, ou do Siriri mato-grossense.

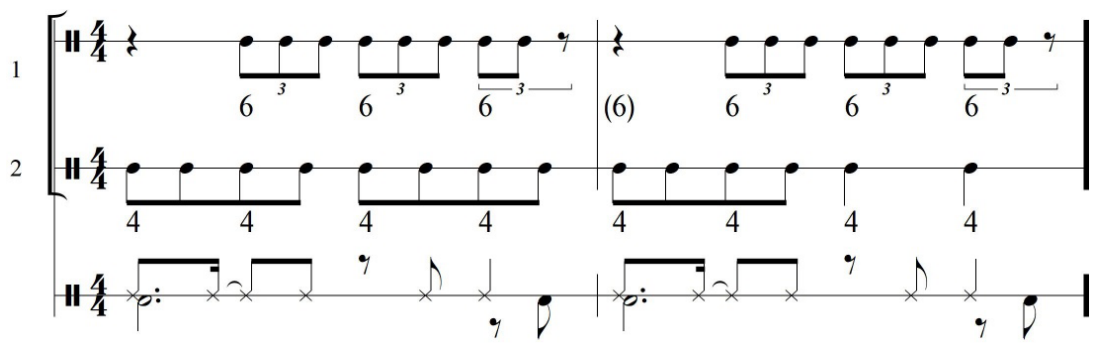

Figura 1 1: Dissonância por agrupamento entre base rítmica e voz no Funk Carioca (exemplo genérico). 


\section{A dissonância não dissonante}

Das inúmeras lacunas que me obriguei a deixar entre os repertórios que trouxe para discussão, alguns aspectos nos saltam mais aos olhos. $\bigcirc$ primeiro deles é a total ausência de exemplos pautados na descoberta que "asseguraria a supremacia da música alemã para os próximos 100 anos" (SCHOENBERG, 1921 apud MORGAN, 1991, p. 187, tradução minha). Uma busca por exemplos em Shoenberg, Berg ou Webern, para ficar no trio hegemonizado da Segunda Escola de Viena, nos revelaria mais imediatamente alguns poucos casos de dissonâncias métricas em peças que não têm nada de serial e, muitas delas, sequer de atonalismo. As 12 Variationen über ein eigenes Thema (Doze variações sobre um Tema original para piano) (1908) de Alban Berg configuram um bom exemplo destes casos, que, não por acaso, é datada anteriormente ao desenvolvimento do sistema dodecafônico de Schoenberg. Nossa questão central aqui é que os procedimentos seriais, especialmente aqueles levados à cabo por Boulez, Stockhausen, entre outros tantos, comumente deturpam, senão o sentido métrico como um todo, certamente sua previsibilidade dentro do contexto da composição. Não há, portanto, como falar em dissonância métrica nestes termos.

Ainda neste sentido, a música eletrônica de pista atual, que frequentemente é associada, devido ao material composicional, com a música eletrônica ou eletroacústica iniciada essencialmente em Paris e Colônia na metade do século passado, guarda, na realidade, relações mais próximas com a música de Stravinsky, Bartók, Pixinguinha e outros do que com as bases serialistas de Schoenberg. A dissonância métrica, grosso modo, recorta o repertório dos "modernistas independentes" destacados por Born (1995). Quanto ao caso brasileiro, Câmara de Castro (2014) reforça nossa relação mais óbvia com Debussy e Bartók, que chegou a chamar a atenção do público de música de concerto para o jazz norte-americano, do que com o conjunto de produções de inspiração germânica, de Schoenberg à Escola de Frankfurt. É preciso observar, ainda, que o ametrismo de peças como a de Ligeti, ilustrada anteriormente, configura uma situação sui generis, dado que as dissonâncias métricas se fazem presentes, ainda que de modo latente.

Da abertura pouco dançável da Mazurka de Itiberê ao Funk de Valesca, Anitta e outros, parece-se acertado observar que estudos muito mais aprofundados quanto às questões de causalidade de cada prática tornam-se necessários. Berlioz nos fala em dissonância rítmica já 
nas primeiras décadas do século XIX pensando e analisando a música europeia de concerto; a hemiola e a polimetria, que demarcam casos importantes de dissonâncias por agrupamento, são vitais na música africana subsaariana estudada por Arom ( 1991 ). É difícil falar, portanto, se em Pixinguinha, para ficar num único exemplo, as dissonâncias métricas têm origem a partir de um ou outro contexto. Tal causalidade, afinal, não compreende o escopo deste artigo, e sua difícil definição acaba por reforçar a ideia de inoperância da distinção entre o erudito e o popular, tendo-se a dissonância métrica como um elemento de convergência.

A partir dos exemplos que listei em ordem cronológica, certas expansões de contextos da dissonância métrica ao longo dos séculos $X X$ e XXI são observadas. Entretanto, afirmar que as dissonâncias métricas aparentemente apenas migram de um contexto ao outro é uma conclusão que, por ora, parece-me equivocada, uma vez que é perfeitamente possivel encontrar exemplos contemporâneos entre si de contextos de produção e recepção distintos - e.g., Trail of Tears (2005), de Luigi Antonio Irlandini, e Octavarium (2005), de Dream Theater.

É preciso observar, finalmente, que a terminologia, aqui, tornase obsoleta, para não dizer equivocada. $\bigcirc$ fundamento de qualquer dissonância - soar transgressora, como algo a ser resolvido simplesmente não existe mais tal qual o paradigma romântico. Uma parte considerável do repertório metricamente dissonante produzido ao longo dos séculos XX e XXI se aproxima do Metro dual proposto por Wilson (2016): estruturas métricas desalinhadas que soam como consonâncias, ao menos para o grupo social que comunga daqueles valores cotidianamente. Dissonância não dissonante; não dissona, soa junto.

\section{Referências}

ADAMS, John C. Short Ride in a Fast Machine. New York: Boosey \& Hawkes, 1986. I Partitura.

AROM, Simha. African Polyphony and Polyrhythm: Musical Structure and Methodology. Cambridge: Cambridge University Press, 1991. 
AUCÉ, Marc. Não lugares: introdução a uma antropologia da supermodernidade. Tradução: Maria Lúcia Pereira. 9 ed. Campinas: Papirus, 2013.

BARTÓK, Béla. Music for Strings, Percussion and Celesta. New York: Boosey \& Hawkes, 1939. I Partitura.

BÉHACUE, Gerard. "Música 'Erudita”, 'Folclórica' e 'Popular' do Brasil: Interações e Inferências para a Musicologia e Etnomusicologia Modernas." Latin American Music Review / Revista De Música Latinoamericana, vol. 27, n. 1, p. 57-68, 2006.

BENJAMIN, William. "Hypermetric Dissonance in the Later Works of Robert Schumann." In: KOK, Roe-Min; TUNBRIDCE, Laura (Eds.). Rethinking Schumann. New York: Oxford University Press, 201 1, p. 206-234.

BERLIOZ, Hector. "Strauss: Son Orchestre, Ses Valses - De L'Avenir Du Rhythme". In: Journal de Débats, 2015 [Nov. 1837]. Disponivel em: $<$ http://www.hberlioz.com/fevilletons/debats37/|1 $10 . h t m>$. Acesso em: 16/03/2019.

und Härtel, 1900. I Partitura.

BERRY, Wallace. Structural Functions in Music. New York: Dover Publications, 1987.

BESSA, Virgínia de Almeida. A escuta singular de Pixinguinha: história e música popular no Brasil dos anos 1920 e 1930. São Paulo: Alameda, 2010.

BIAMONTE, Nicole. "Formal Functions of Metric Dissonance in Rock Music". Journal of Society for Music Theory, v. 20, n. 2, 2014.

BORN, Georgina. Rationalizing culture: IRCAM, Boulez, and the institutionalization of the musical avant-garde. London: University of California Press, 1995.

BOSI, Alfredo. Plural, mas não caótico. In: BOSI, Alfredo. Cultura brasileira: temas e situações. 2. ed. São Paulo: Ática, 1992a. 

Letras, $1992 b$.

Dialetica da colonização. São Paulo: Companhia das

BOSWORTH, William Thomas. Metrical Dissonance in Brahms's Second Piano Trio, Opus 87 in C Major. Dissertação (Mestrado). College of Arts and Law, The University of Birmingham, Birmingham, 2012.

BUTLER, Mark J. Unlocking the Groove: Rhythm, Meter, and Musical Design in Electronic Dance Music. Bloomington and Indianapolis: Indiana University Press, 2006.

CACERES, Guillermo; FERRARI, Lucas; PALOMBINI, Carlos. "A era Lula/Tamborzão: política e sonoridade". Revista do Instituto de Estudos Brasileiros, Brasil, n. 58, p. 157-207, 2014.

CALDI, Alexandre. "Os contrapontos para sax tenor de Pixinguinha nas 34 gravaçöes com Benedito Lacerda - primeiras reflexöes". Cadernos do coloquio, p. 82-90, abr. 1999. Disponível em: <http://www.seer.unirio. br/index.php/coloquio/article/view//3 > . Acesso em: 27/03/2019.

CASTRO, Marcos Câmara de. "Música erudita e música contemporânea: valor estético e valor simbólico". In CONCRESSO DA ANPPOM, XX, Florianópolis. Anais... Florianópolis, ANPPOM, 2010. p. 568-572.

- "Alguns escritos de Debussy e Ravel, a Carta Aberta de Guarnieri e as sagradas escrituras da Escola de Frankfurt". In CONGRESSO DA ANPPOM, XXIV, São Paulo. Anais... São Paulo, ANPPOM, 2014.

CANCLINI, Néstor García. Culturas hibridas: estrategias para entrar y salir de la modernidad. Buenos Aires: Sudamericana, 1995.

CARONE, Iray. "Adorno e a educação musical pelo rádio". Educação \& Sociedade, v. 24, n. 83, Campinas, p. 477-493, 2003. 1998.

CERTEAU, Michel de. La culture au pluriel. Paris: Editions du Sevil,

$\mathrm{COHN}$, Richard. "Metric and Hypermetric Dissonance in the Menuetto of Mozart's Symphony in G minor, K. 550". Intégral, v. 6, p. 1-33, 1992. 
DODSON, Alan. "Metrical Dissonance and Directed Motion in Paderewski's Recordings of Chopin's Mazurkas". Journal of Music Theory, v. 53, n. 1, p. 57-94, 2009.

FISCHERMAN, Diego. Efecto Beethoven: complejidad y valor en la música de tradición popular. Buenos Aires: Paidós, 2004.

FRANCFORT, Didier. Músicas populares e músicas eruditas: uma distinção inoperante? Tradução de Marcos Câmara de Castro. Tradução de: La musique savante manque à notre désir (Rimbaud, Illuminations). [S.I]: [s.n.], 2014. Disponivel em: <https://bit.ly/2BGfyVV> . Acesso em: 16/05/2019.

COMES, Plínio Freire. "Notas sobre a mediação entre o erudito e o popular". Revista de História. São Paulo, n. 125-126, p. 05-80, 1992.

CUMBOSKI, Leandro. "Dissonâncias métricas em obras do início do século XX: o caso de L'Histoire du Soldat, de lgor Stravinsky". In CONCRESSO DA ANPPOM, XXVII, Campinas-SP. Anais... Campinas-SP, ANPPOM, 2017.

"Aspectos da Teoria da Dissonância Métrica”. In CONGRESSO DA ANPPOM, XXVIII, Manaus-AM. Anais... Manaus-AM, ANPPOM, 2018.

CUMBOSKI, Leandro; MOREIRA, Adriana Lopes da Cunha. "Entre apoios e impulsos: uma revisão histórico-analítica do metro musical em textos teóricos". Opus, v. 24, n. 3, p. 271-292, set./dez. 2018.

HOLST, Gustav. The Planets: Arranged for two pianos by the composer. London: J. Curwen \& Sons Limited, 1979. I Partitura.

ITIBERÊ, Brasílio. 6ª Mazurka, Op. 31. Milão: F. Lucca, ca. 1882. I Partitura.

KREBS, Harald. Fantasy Pieces: metrical dissonance in the music of Robert Schumann. New York: Oxford University Press, 1999.

"Functions of Metrical Dissonance in Schubert's Songs". Musicological Explorations, University of Victoria, v. 14, p. 1-26, 2014. 
LERDAHL, Fred; JACKENDOFF, Ray. A Cenerative Theory of Tonal Music. Cambridge: The Massachusetts Institute of Technology, 1983.

LONDON, Justin. Hearing in Time: Psychological Aspects of Musical Meter. 2 Ed. New York: Oxford University Press, 2012.

LOVE, Stefan Caris. "Subliminal Dissonance or "Consonance"?" Two Views of Jazz Meter. Music Theory Spectrum, v. 35, n. 1, p. 48-61, 2013.

MALIN, Yonatan. Songs in Motion: Rhythm and Meter in the German Lied. New York: Oxford University Press, 2010.

MARTIN-BARBERO, Jesus. Dos meios as mediações: comunicação, cultura e hegemonia. Rio de Janeiro: Editora da UFRJ, 2001.

MCCANDLLES, Gregory Richard. Rhythm and Meter in the Music of Dream Theater. Tese (Doutorado). College of Music, The Florida State University, Tallahassee, 2010.

MENESES, Paulo. "A cultura no plural". Sintese Nova Fase, v. 20, n. 63, p. $445-458,1993$.

MORGAN, Robert P. Twentieth-century music: a history of music style in modern Europe and America. New York: W. W. Norton and Company, 1991.

NAZARETH, Ernesto. Odeon: tango brasileiro. Rio de Janeiro/São Paulo: E.S. Mangione, 1968. I Partitura.

PIESLAK, Jonathan. "Re-casting Metal: Rhythm and Meter in the Music of Meshuggah". Music Theory Spectrum, Vol. 29, No. 2, 2007, p. 219-245.

REICH, Steve. Piano Phase: for two pianos or two marimbas. London: Universal Edition, 1980.

RILEY, Terry. In C. Tucson: Celestial Harmonies, 1989. I Partitura.

ROSA, Luciana Fernandes; BERG, Silvia Maria Pires Cabrera. "Entre o erudito e popular: aproximações e distanciamentos na formação da 
música urbana brasileira". Revista da Tulha, Ribeirão Preto, v. 4, n. 1, pp. 69-90, 2018.

RÖSSEL, Jörg; OTTE, Gunnar. "Culture". In: Cerman Data Forum (RatSUD). Building on Progress: Expanding the Research Infrastructure for the Social, Economic, and Behavioral Sciences, I st ed., Verlag Barbara Budrich, p. 1 153-1172, 2010.

SÈVE, Mário; GANG, David (Coord.). Choros duetos: Pixinguinha e Benedito Lacerda. São Paulo: Irmãos Vitale, 2010-201 1, 2 v.

SMITH, Peter. "Brahms and the Shifting Barline: Metric Displacement and Formal Process in the Trios with Wind Instruments." In: BRODBECK, David (Ed.). Brahms Studies. Lincoln: University of Nebraska Press, p. 191229, 2001.

SOUZA, Arão de Azevêdo. "Debates sobre cultura, cultura popular, cultura erudita e cultura de massa". In XII CONCRESSO DE CIÊNCIAS DA COMUNICAÇ̃̃O NA REGIÃO NORDESTE. Anais... INTERCOM, Sociedade Brasileira de Estudos Interdisciplinares da Comunicação, Campina Grande, 2010.

VAN DEN TOORN, Pieter C. Stravinsky and the Russian Period: Sound and Legacy of a Musical Idiom. Cambridge: Cambridge University Press, 2012 .

VILLA-LOBOS, Heitor. Choros (NN. I): à Ernesto Nazareth. Paris: Max Eschig, 1960. 1927.

Choros (No. 2): à Mário de Andrade. Paris: Max Eschig,

WATERS, Keith. "Blurring the Barline: Metric Displacement in the Piano Solos of Herbie Hancock". Annual Review of Jazz Studies, v. 8, p. 19-37, 1996.

UILSON, Andrew. Dual-Aspect Meter: A Theory of Metrical Consonance, Dissonance, Weight, and Variety. Tese (Doutorado). Graduate Faculty in Music, City University of New York, New York, 2016. 
UISNIK, José Miguel. "Entre o erudito e o popular". Revista de História, São Paulo, n. 157, p.55-72, 2007.

O som e o sentido: uma outra história das músicas. 3 ed. São Paulo: Companhia das Letras, 2017.

YESTON, Maury. The Stratification of Musical Rhythm. New Haven and London: Yale University Press, 1976.

ZUMTHOR, Paul. A Letra e a Voz: A literatura medieval. Tradução: Amálio Pinheiro, Jussara Pires Ferreira. São Paulo: Companhia das Letras, 1993.

\section{Sobre o autor}

Leandro Gumboski é Licenciado em Música pela Faculdade de Artes do Paraná/UNESPAR (2012) e Mestre em Música (MusicologiaEtnomusicologia) pela Universidade do Estado de Santa Catarina (20/4). Atualmente é docente efetivo do Instituto Federal do Paraná - Campus Paranaguá (2015-) e doutorando em música (Musicologia/ Teoria e Análise) pela Universidade de São Paulo (2018-), sob orientação de Adriana Lopes da Cunha Moreira. Como pesquisador, tem atuado na área de Musicologia, com ênfase em Teoria e Análise Musical, especialmente com o estudo de modelos teóricos e analíticos voltados à compreensão de estruturações temporais. leandro.gumboski@ ifpr.edu.br

Recebido em 04/07/2019

Aprovado em 03/09/2019 